\title{
Influence of the Supporting Electrolyte on the Electrochemical Polymerization of 3,4-Ethylenedioxythiophene. Effect on $p$ - and $n$-Doping/Undoping, Conductivity and Morphology
}

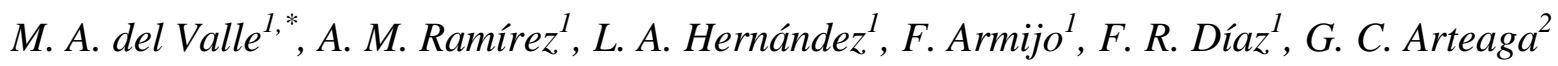 \\ ${ }^{1}$ Pontificia Universidad Católica de Chile, Facultad de Química, Departamento de Química \\ Inorgánica, Laboratorio de Electroquímica de Polímeros (LEP), Vicuña Mackenna 4860, 7820436, \\ Macul, Santiago, Chile. \\ ${ }^{2}$ Universidad del Sinú Elías Bechara Zainum, Facultad de Ingeniería, Grupo DEMA, cra 1w N 38- \\ 153, Montería, Colombia. \\ *E-mail: $\underline{\text { mdvalle@uc.cl }}$
}

doi: $10.20964 / 2016.08 .46$

Received: 11 May 2016 / Accepted: 17 June 2016 / Published: 7 July 2016

\begin{abstract}
A systematic study of the influence of the type of electrochemical perturbation, in the presence of various salts, namely $\mathrm{LiClO}_{4}, \mathrm{TBAClO}_{4}, \mathrm{TBAPF}_{6}, \mathrm{TEAPF}_{6}$, LITFMS or TBATFMS in acetonitrile, on the electropolymerization of 3,4-ethylenedioxythiophene on platinum was accomplished. Poly(3,4ethylenedioxythiophene) (PEDOT) electrodeposits were electrochemically characterized in situ while prepared by cyclic voltammetry and constant potential techniques from solutions containing the monomer and each of the abovementioned electrolytes. $n$ - and $p$-doping/undoping processes (reversibility, stability and charge) and nucleation and growth mechanisms, that subsequently will be complemented and compared using conductivity measurements (four point probe method) and morphological characterization by SEM and AFM, were studied. It was verified that the volume of the supporting electrolyte ions and the waveform applied for the electrosynthesis, correlate directly with conductivity, morphology and reversibility, charge and stability of the generated polymeric coatings. Considering its likely aplication for the development of batteries, assessing by potentiodynamic method during 1000 cycles of charge/discharge in $0.10 \mathrm{~mol} \mathrm{~L}^{-1} \mathrm{LiCl}$ aqueous solution, it was finally corroborated that films obtained from 5 voltammetric cycles in the presence of $\mathrm{TBAPF}_{6}$ are the most suitable candidates by showing, besides of reversibility, the greatest charge, with a stability larger than $95 \%$. In any case, the results of this study allow selecting the electrosynthesis working conditions depending on the wanted application of the PEDOT modified electrode.
\end{abstract}

Keywords: 3,4-ethylenedioxythiophene, electropolymerization, $p$-doping, $n$-doping, poly(3,4ethylenedioxythiophene), nucleation and growth mechanism.

\section{$\underline{\text { FULLTEXT }}$}


(C) 2016 The Authors. Published by ESG (www.electrochemsci.org). This article is an open access article distributed under the terms and conditions of the Creative Commons Attribution license (http://creativecommons.org/licenses/by/4.0/). 